\title{
Study on Cable Stayed Bridge and Its Application in India
}

\author{
Shantnu \\ M. Tech. Scholar \\ Structural Engineering \\ SRK University \\ Bhopal, India \\ Shantnu1@gmail.com
}

\author{
Dr. Pankaj Singh \\ Professor \\ Structural Engineering \\ SRK University \\ Bhopal, India
}

\begin{abstract}
Bridges are the structures built across any obstacles to connect its two end to allow free movement. Bridges have played a vital and key role in the development of human civilization since thousand of years. Existence of ram setu is an example of presence of bridge technology in ancient time. Bridges are often classified as arch bridge, suspension bridge, Girder Bridge, truss bridge and cable stayed bridge. Advancement in technology has led to development from arch bridge to cable stayed bridge. In present time cable stayed bridge technology are the most favorite and preferable type across the world. Cable stayed bridge construction methodology has various advantages over other types including important one like of being economical and aesthetical appearance. This paper is an attempt to analyze the cable stayed bridge and its various use in India.
\end{abstract}

Keywords- Bridge deck, Cable stayed bridge,

\section{INTRODUCTION}

The idea of providing support to a bridge deck by using inclined stays was proposed way behind in 1784 by C. J. Loscher, German carpenter. It was imagined as a timber bridge as it consists of timber stays attached to a timber tower. sadly, during the start of the cable-stayed system, the engineers were unable to calculate the forces in the stays also they were not able to realize or control the equilibrium of these vastly indeterminate systems [1]. at that time Unsuitable materials such as timber, round bars or chains were used for stays. The stays constructed in this manner were, therefore, of low strength material and could not be fully tensioned. In a slack condition they required substantial deformation of the deck before they could participate in taking the tensile load for which theywere intended [2]. first recent steel cable-stayed bridge was www.ijoscience.com constructed in Sweden in 1955 by a German contractor. Bridge named as Stromsund Bridge. Although the cable stayed Tempul Aqueduct in Spain, designed by Torroja, was completed in 1925, the first modern prestressed concrete cable-stayed bridge structure was Morandi's Lake Maracaibo Bridge in Venezuela, completed in 1962. Cable stayed bridge are might be chosen for the solution of vast and dense traffic problems but it provides at the same time a faster track for development of a country. since it has advantages of lack of disturbance over the present infrastructures and landscapes it is most favorite selection for engineers. Cable stayed bridge satisfies the necessities of bridge with longer span [3][4].

\section{COMPONENT OF CABLE STAYED BRIDGE}

A typical cable stayed bridge are structural unit consisting of continuous girder or deck with one or more towers erected in the middle of the span, foundation and cable system. vertical loads in the bridges are mainly carried by girder. staying cables provide in between supports for the girder thus it can cover a long distance [5].

From towers, cables are strained out diagonally in downward direction and support the stiffening girder which are anchored at pylon. Pylons are placed on main piers to transfer the cable forces to the foundation system. All members are primarily under axial forces, with cables under tension force while the pylon \& girder under compression force. Axially loaded members are generally more efficient than flexural members. Cable stay bridges are classified by its span numbers, number of towers, type of girder, number and types of cables [6]. 


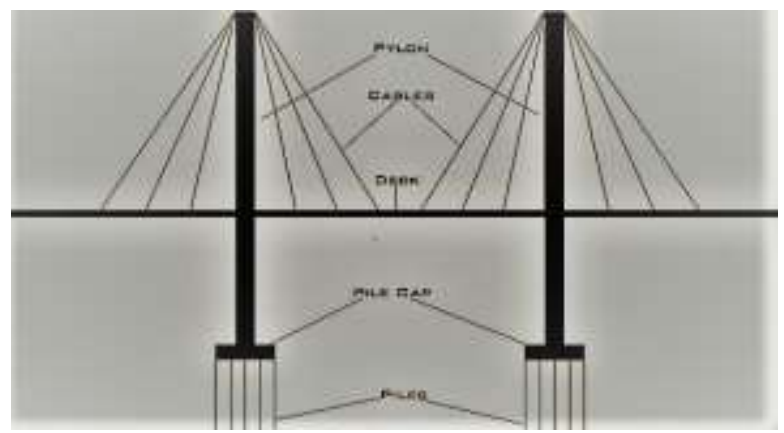

Fig.1. Cable Stayed Bridge

\section{ARRANGEMENT OF CABLES}

Harp Pattern. In the harp system the cables are connected to the tower at different heights. According to the varied longitudinal arrangements, cable-stayed bridges are often divided into three basic systems radial, fan and harp pattern . However, except from long span structures, configuration of cables doesn't have a serious effect on the performance of the bridge but it's important while considering lateral forces [7]. Harp Pattern: this system has the various cables connected to the tower at dissimilar heights and are set parallel to each other. This pattern is more pleasing in look wise as no intersection of cables occurs even in diagonal direction. (figure I). But this system causes bending moments within the tower and as a result the complete Pattern tends to be less stable. this system can't obtain equilibrium condition with the cable itself, but this is balanced by the bending stiffness of stiffening girder and therefore the pylons compensate steadiness which was reduced within the cable. A complete stabilization in this system are frequently obtained when intermediate supports are placed inside spans beneath the anchor points of cable.

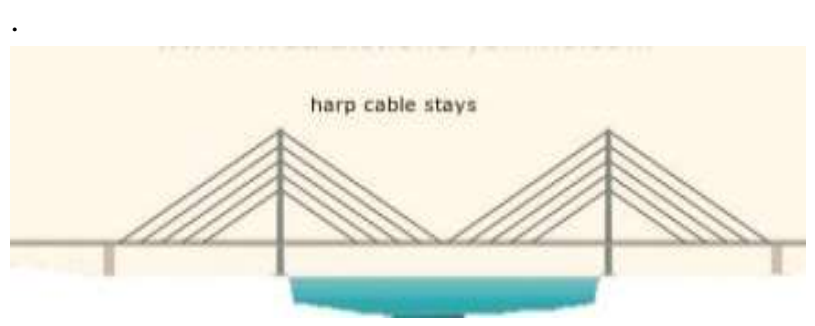

Fig.2. Harp Cable Stayes

Fan Pattern: A Fan-type cable arrangement is also very eye-catching, particularly in a case of a mono or one plane cable slope of cables are steeper, axial force inside the girder, which is addition of all horizontal components of cable forces, is less. This pro is very useful www.ijoscience.com for longer-span bridges where compression in the girder has an effect on the design.

this arrangement is usually considered the simplest as per its arrangement, as the highest inclination of each cables are frequently reached. This system concludes to the foremost effective support of the vertical deck force and thus leads to the smallest achievable diameter of cable. Fan pattern has been implemented with only towers of A shape. Tower can be in the center of the bridge or on the side and has a formal variety in comparison to harp patterns. In this type, all cables connect to the peak of the towers. This fan design is structurally superior with minimum moment to the towers. modified fan pattern is normally preferred in practical, especially where cables requirement are more. modified fan arrangement have cables finishing near the peak of the tower but are spaced from each other sufficiently to let better termination, better environment protection, and good access to each cables for maintenance.

\section{fan cable stays}

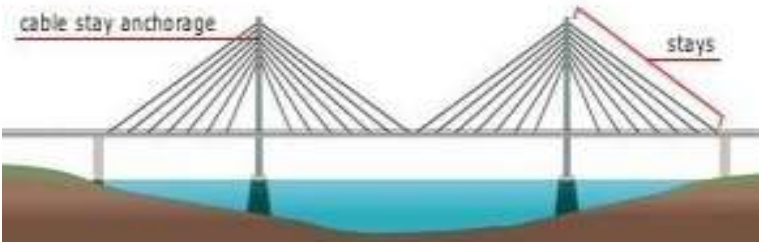

Fig.3. Fan Cable Stayes

Star pattern : this type of pattern have cables being spaced separately on the tower similar to harp design, but difference in star pattern is cables connect to 1 point or a different closely spaced points on the girder. It is rare design

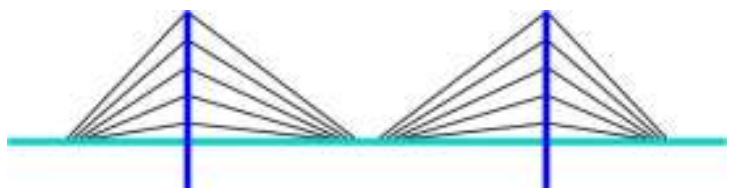

Fig.4. Star Cable Stayes

More than 50 percentage of the bridges are constructed using harp pattern and it's mainly because of easiness of work furthermore giving high speed of execution in this. Radial pattern isn't generally used and only a couple of bridges are built using this technique as high accuracy required within the implementation of cables. 


\section{APPLICATION OF CABLE STAYED BRIDGE IN INDIA}

(1) Akkar Bridge : This is the first cable stayed bridge of Asia in which deck and pylon were designed wholly in reinforced concrete it consists of parallel wires and the cables are filled with polyurethane to prevent the wires from corrosion. Length of span of this bridge is $-77 \mathrm{~m}$ and width being $11.10 \mathrm{~m}$. its tower height is $54.60 \mathrm{~m}$

(2) Vidyasagar Sethu: It is one of the longest cable stayed bridge in India was made in 1943. This bridge consists of 121 cables in a fan arrangement. The deck is made up of composite steel reinforced concrete. Length of bridge is 823 meters and deck width of 35 meters. Pylon are 127 meter high.

(3) New Yamuna Bridge Allahabad: This project involves the construction of a $630 \mathrm{~m}$ cable-stayed bridge. The total length of bridge is $1.51 \mathrm{k}$ m having longest span of $260 \mathrm{~m}$ supported by cables which stays in a concrete anchor bridges.

(4) Chiraiyatand bridge patna: The 4 lane cable-stayed over bridge is the second of its kind in the country built with German technology. bridge is $110 \mathrm{~m}$ long and $20 \mathrm{~m}$ wide

(5) The Bandra-Worli Sea Link : it is also an example of cable-stayed bridge with use of pre-stressed concrete-steel in its construction the length of the bridge is $5.6 \mathrm{~km}$ and width is $40 \mathrm{~m}$.

(6) Raja bhoj bridge :The 300 metre Raja Bhoj Setu is one of newest construction example of cable stayed bridge in india

(7) Yamuna bridge delhi: the under construction bridge is a Cantilever spar cable-stayed bridge in this bridge cables are arranged in a combination of radial and semi-harp pattern. cables are spaced at a distance on the pylon, likewise harp design, but connects single point or various points separated by small distance on the deck. Length of bridge is 675 $\mathrm{m}$ with height of tower $165 \mathrm{~m}$. bridge is expected to complete in 2019.

\section{CONCLUSION}

In above discussed three patterns, fan and harp patterns have most number in comparison to the radial pattern. Almost half of total being constructed are harp pattern and this is due to the ease of work and the less time consumption in construction by this pattern. Radial pattern isn't generally used and very few of bridges have been built using this due to the high demand of accuracy needed in the arrangement of cables. slope is also high in contrast with harp patterns. This consideration leads to reduction in material used in bridges and results in a decrease in weight of bridges. even though the radial pattern has advantages, it is not widely used due to the implementation problems. Since cables are attached to one point at the top of the tower, if they are not executed carefully, they might leads to anchor.

\section{REFERENCES}

[1] Wang, P. H., Tseng, T. C., and Yang, C. G. "Initial Shape of Cable-Stayed Bridges." Journal of Computers and Structures, 41(1), 1993, pp. 111- 123.

[2] Wang, P. H., and Yang, C. G. "Parametric Studies on Cable-Stayed Bridges." Journal of Computers and Structures, 60(2), 1996, pp. 243-260.

[3] Chena, D. W., Au, F. T. K., Cheng, Y. S., Cheung, Y. K. , and Zheng, D. Y. "Determination of Initial Cable Forces in Prestressed Concrete Cable- Stayed Bridges for Given Design Deck Profiles using The Force Equilibrium Method." Journal of Computers and Structures, 74, 2000, pp. 1-9.

[4] Mozosa, C. M., and Aparicio, A. C. "Parametric Study on The Dynamic Response of Cable Stayed Bridges to The Sudden Failure of A Stay; Part I. http://www.iaeme.com/IJCIET/index.asp 1147 editor@iaeme.com Nithesh. K, Kiran K. Shetty and Premanand Shenoy Deck; Part II: Bending Moment Acting On The Pylons And Stress Onthe Stays." Journal of Engineering Structures, 32, 2010, pp. 32883312.

[5] Agrawal, A. P."Cable-Stayed Bridges-Parametric Study." Journal of Bridge Engineering, American Society of Civil Engineers, 2(2), 1997, pp. 61-67.

[6] Raheem, S. E. A., Shafy, Y. A., Seed, F. K. A., and Ahmed, H. H. "Parametric Study on Nonlinear Static Analysis of Cable Stayed Bridges." Journal of Engineering Sciences, 41(1), 2013.

[7] Nadkarni, P. R., Salunke, P. J., and Narkhede, T. N. "Parametric Investigation of Cable Stayed Bridge Using Macro Based Program." International Journal of Research in Engineering and Technology, 4(9), 2015, pp.207-210. 